\title{
DESIGN AND ANALYSIS OF SWIRL IN ACETYLENE ASPIRATED DIESEL ENGINE AND ITS EFFECTS ON PERFORMANCE \& EMISSIONS
}

\author{
Shaik Khader Basha ${ }^{1}$, P. Srinivasa Rao ${ }^{2}$, K. Rajagopal ${ }^{3}$, Ravi Kumar Kotturi ${ }^{4}$
}

\begin{abstract}
The major challenges in the field of automobile industry are controlling of pollution, low fuel consumption, non usage of fossil fuels, comfort design to meet the growing needs, low cost and long life. Those challenges can be meet by proper combustion of fuel, selection of appropriate materials for the engine parts, reduction of the whole weight, non usage of fossil fuels, innovative design in construction and working principle of engine, use various alternative fuels and different fuel injecting techniques to develop pollution free and low cost engines. In present scenario the research level has reached to peak positions in the area of IC Engines as per the needs and demands of control of emissions. This paper deals with experimental investigation of performance of the engine as well as exhaust emissions by supplementing Acetylene gas with diesel, design and CFD analysis of mixing box and also applying Exhaust gas recirculation technique. A standard Variable compression ratio engine is selected and the engine first runs with only diesel and secondly Acetylene of different volumes and air is mixed in a new designed mixing box and supplied to the engine cylinder. The EGR technique is also applied in this experimental work to evaluate and quantify the engine performance characteristics and emissions of exhaust. Based on the study and analysis obtained results of experiments it is possible to run the diesel engine along with Acetylene without compromising the efficiency at lowest acceptable pollution levels.
\end{abstract}

Keywords - Engine performance, Emission control, mixing box, CFD analysis and EGR technique.

\section{INTRODUCTION}

The compression ignition (CI) engine is one of the most widely used in automobile engines which gives better power outputs and excellent performance. The fuels extracted from renewable energy sources are having high selfignition temperatures and therefore those fuels suitable for spark ignition engines however those fuels may not be directly used in diesel engines. Nevertheless diesel engines are so designed and used with considerable quantity of gaseous fuels with dual fuel modes. Rapid industrialization, less fossil fuel reserves and day by day worsening of environmental pollution insisted to search for few more alternatives from conventional fuels results in several fuels like Compressed natural gas, Acetylene, Liquid petroleum gas, Bio diesel ethanol, some vegetable oils, and other such type of biomass resources. Alternative fuels of have higher calorific value, and non-polluting should be easily available and ready to use. The quality of good alternative fuels can be measured in terms of effects on environment, performance parameters and energy produced. Acetylene gas is having many such qualities among the available alternative fuels made suitable in selection of an alternative fuel. Acetylene gas has high calorific value and excellent combustion efficiency. The significant challenge in Acetylene engine is to control the Oxides of nitrogen (NOx) emissions. Lean-burn technologies including conventional and advanced diesel combustion techniques and strategies will give motivating results. Latest technologies includes advanced combustion techniques and strategies

${ }^{1}$ Department of Mechanical Engineering, Al-Habeeb College of Engineering \& Technology, Hyerabad, India

${ }^{2}$ Curl Vee Technolabs, Hyerabad, India

${ }^{3}$ Vice-Chancellor, Sri Krishna Devaraya University, Anantapuram, Andhra Pradesh, India

${ }^{4}$ Department of Mechanical Engineering, Al-Habeeb College of Engineering \& Technology, Hyerabad, India 
which make use of higher levels of dilution to decrease in-cylinder formation of NOx as well as post-combustion control of emission devices, however carrying the acetylene cylinder and backfiring strictly restricted to select acetylene as a alternative fuel in automobiles. We have proposed a system by which the acetylene gas may be used as an internal combustion engine fuel with similar performance as compared with petrol engine.

Sharma P.K. et al. worked with acetylene as an alternative fuel in internal combustion engines. They have done experiments on Spark Ignition engine using primary fuel as acetylene and the secondary fuel as alcohol. The end results showed that alcohol should to be introduced so as to control the temperature inside the combustion chamber [1]. Nagarajan G and Lakshamanan T conducted several experiments to study the performance characteristics and emission distinctiveness of direct injection diesel engine in dual fuel mode by timed manifold injection technique to supply acetylene at different values of flow rates. Results showed the best condition possible is in manifold injection technique is $10^{\circ}$ ATDC with $90^{\circ}$ crank angle injection interval. A constant quantity of 3 lpm of acetylene is inducted in to the inlet manifold in dual fuel mode with ignition source as diesel for various loads during experiments and obtained results. The results showed brake thermal efficiency in acetylene inducted mode was found lower than pure diesel operation at 100\% load.[2] G.Nagarajan and T.Lakshamanan done experiments on a four stroke diesel engine and aspirated the acetylene along with air at different values of flow rates in dual fuel mode of operations. They conducted the experiment on a air cooled single cylinder, direct injection (DI), compression ignition engine designed to develop the rated power output and operated at same speed under different load conditions. Aspiration of acetylene results with low thermal efficiency reduction in Smoke, $\mathrm{CO}$ and $\mathrm{HC}$ emissions as compared to with pure diesel operation. Due to the high rates of combustion, the NOx emission significantly raised with acetylene induction. Peak cylinder pressure and maximum pressure rise rate is also increased in the acetylene mode of operation because of high flame speed. Lastly it was concluded that induction of acetylene could significantly increase the smoke, $\mathrm{HC}$ and $\mathrm{CO}$ emissions with a low compromise in efficiency [3]. Mahla S.K. et al. done experiments to study the performance and emission characteristics of Direct Ignition diesel engine in dual fuel manner by aspiration of Acetylene with set quantity of $12 \mathrm{lpm}$ in the inlet manifold with diethyl ether blends (B10, B20, and B30) mixed with ignition source as diesel. It was found that in two fuels operation along with the help of DEE as pilot fuel to be diesel blend exhibits fine engine performance which match up to diesel fuels. Sole acetylene fuel in HCCI mode resulted higher thermal efficiencies in a broad range of $\mathrm{B}_{\text {mep. Thermal efficiencies are }}$ comparable to the pure diesel engine and a minor increment in brake thermal efficiency was noted with optimized EGR technique of operation and the intake temperature charge and value of EGR have to be controlled depend on the engine output and at higher $\mathrm{B}_{\text {mep }}$ hot EGR makes the engine to knock[4]. Gunea, Razavi, and Karim et al. Done several experiments on a 4-stroke and single cylinder, direct injection diesel engine fuelled with natural gas. Experiments were done with pilot fuel as diesel with different cetane numbers to find the effects of pilot fuel quality on ignition delay. The conclusion given that ignition delay of a dual fuel engine mainly depends on quantity of pilot fuel and quality of pilot fuel. Higher cetane number pilot fuels may be used to improve the performance of engines using lower cetane value gas fuels [5]. John W.H. Price explains the explosion of acetylene gas cylinder which occurred in Sydney in the year1993. It causes a failure and leads to serious fragmentation in a cylinder which resulted in a fatality, damage of property and deaths. This paper also explained the failure and the related circumstances affect it. He checked the type of the explosion which occurred and sort out an explanation of that event [6]. Swami Nathan et al. did experiments on only acetylene fuel in HCCI engine and results shown as with

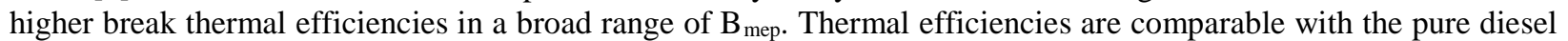
engine and a slight increment in brake thermal efficiency was noted with optimized value of EGR operation. Based upon the output of engine and at high $\mathrm{B}_{\text {mep, }}$ the quantity of hot EGR, the intake charge temperature and amount of cold EGR can to be controlled which leads to knocking. The NOx (oxides of nitrogen) values of and smoke values are lowered by HCCI mode of combustion but Hydro carbon emissions are higher compared with pure diesel fuel engine.

\section{MATERIALS AND METHODS}

\section{Alternative Fuels}

There are so many alternative fuels are available as a substitute to the fossil fuels in IC Engines. Fuels may be categorised into 3 types, viz. liquid fuels, Solid fuels, and gaseous fuels.

Acetylene Gas 
Acetylene $\left(\mathrm{C}_{2} \mathrm{H}_{2}\right)$ is not gas form of air, but a synthesis gas normally produced by the reaction of calcium carbide and water. It was earlier burnt in "acetylene lamps" to lighten the homes and in mining tunnels in 19th century. Acetylene is a gas of hydrocarbons, and colourless, with a strong garlic odour, is unstable, very highly combustible in nature, and produces hot flames (about $3000^{\circ} \mathrm{C}$ or $5400^{\circ} \mathrm{C}$ ) when reacted with oxygen. Conventionally acetylene may generated simply by reacting the calcium carbide with $\mathrm{H}_{2} \mathrm{O}$. The reaction is occurring continuously and can be generated without any special apparatus or equipment. Such conventionally produced acetylene has been used for lightening in mine areas by the street vendors in earlier days usually. Industrial applications of acetylene gas as a fuel in motors and lighting sources, however, the usage have been almost nonexistent. Now a days, the usage of acetylene gas as a fuel has been limited to acetylene gas torches for gas welding and welding-related uses.

\section{Methodology}

The experimental arrangement is shown in fig. 1 which illustrates an engine setup. The Engines details are tabulated in Table.1. The tests were carried out on a naturally aspirated with single cylinder, 4-stroke, direct-injection, highspeed engine with water cooled. The engine's nominal injection timing is 19 degrees crank angle before top dead centre and fixed the same throughout all tests. The engine is built-up with a data acquisition system for the cylinder pressure (bar) measurement. The diesel is injected in combustion chamber in a regular manner and Acetylene gas from the acetylene generator is supplied in to a new designed mixing box where air from the atmosphere is supplied and mixed. Suitable acetylene gas to diesel fuel ratio could give the better performance characters and hence leads to boost up the thermal efficiency. The flow rate of acetylene gas was controlled by flow control needle valve and was measured with the help of fine tuned gas flow rate meter. The diesel flow was measured by noting the time for fixed volumes of diesel consumed by the test rig. To determine the pressure variations, a pressure transducer fixed. A thermocouple is used to determine the temperature of exhaust gases from the engine. Smoke meter or smoke detector was used for the measurement of smoke from the combustion chamber. The rate of heat release and other parameters of combustion were calculated by using software for the accurate results. The combustion parameters, performance parameters and emission distinctiveness of the diesel engine were calculated and compared with pure diesel fuel process

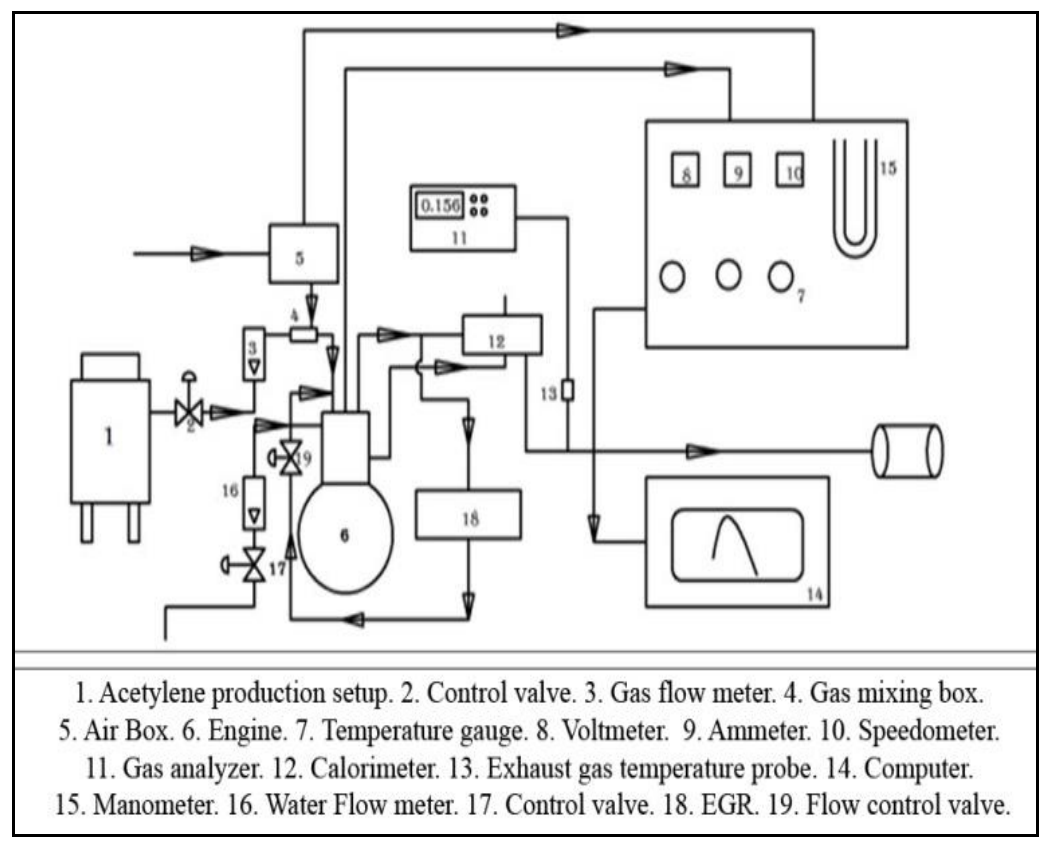

Fig. 1 Schematic diagram of Experimental setup with EGR. 
Table.1. Engine Specifications

\begin{tabular}{ll}
\hline PARTICULARS & SPECIFICATIONS \\
\hline Type & Vertical, 4-Stroke Cycle, Water cooled \\
Make & Kirloskar Oil Engines \\
Model & TV-1 \\
Type of ignition & Compression Ignition \\
Rated power $(\mathrm{kw})$ & 3.5 \\
Constant speed (rpm) & 1500 \\
Bore (mm) & 87.5 \\
Stroke (mm) & 110 \\
Compression ratio range & 14.5 To 22.0 \\
Dynamometer & Eddy Current Type \\
\hline
\end{tabular}

\section{Modelling and Analysis of Mixing Box}

The science which deals with the prediction of behavior of flow of fluid, transfer of heat, chemical reactions, transfer of mass and their processes governing equations will solve by numerical process is Computational fluid dynamics. The CFD will estimate the behavior of combinations of fluid flows in complex systems where two or more fluids mix with each other based on the boundary conditions, velocities and pressures of the different fluids The software will help and support in better control of flows, how the fluids interacting, drop in velocities and pressures etc which will give the guidelines in the selection of optimum shapes without conducting the experiments in the laboratory. Since its software tool with which we can select many variables like dimensions, boundary conditions, velocities and pressures, different materials etc. In present work for proper mixing of Air and Acetylene is essential to supply the engine for complete combustion in order to minimize the emissions. To find out the optimum shape of the mixing box three different configurations are selected such as rectangular mixing box with two inlets and one outlet, Triangular mixing box with two inlets and one out let and a modified Triangular mixing box with three inlets and one outlet are for optimum shape of the mixing box. In the pre processor the 3D model is generated in Gambit 3.4 and meshing is done using Gambit Grid elements are hexahedral 300600. The boundary conditions are Pressure Inlet and velocity outlet by assuming walls of the box are adiabatic stationary and with 3D model, Unsteady Eulerian solver and the processor (Solver) is Ansys Fluent: 6.3. The various line diagrams of mixing boxes shown below.

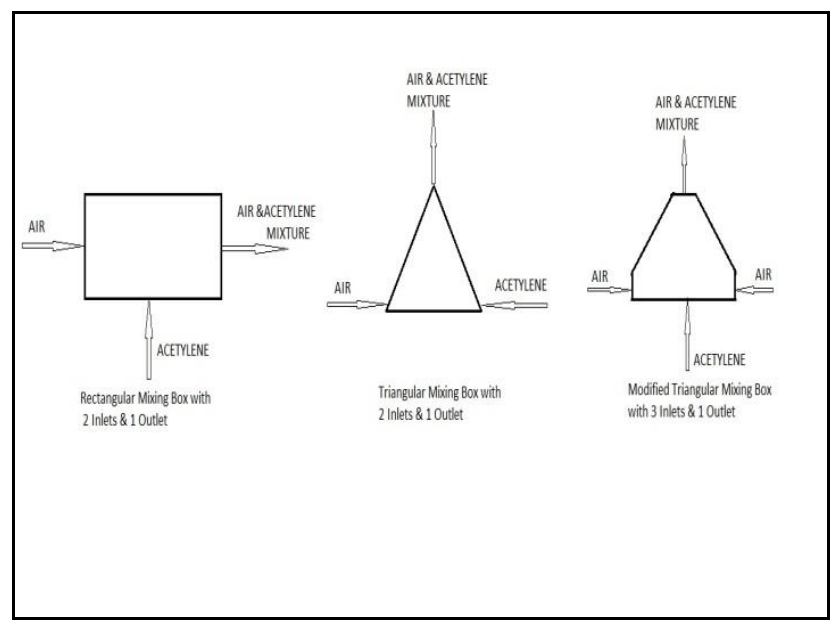

Fig.2 Line diagrams of various mixing boxes

Out of the above three said models the Triangular mixing box with three inlets out of which two inlets are for Air and one inlet is for Acetylene and the outlet is for the mixture of air and acetylene to the engine gave improvement in mixing compared to the other configurations. 


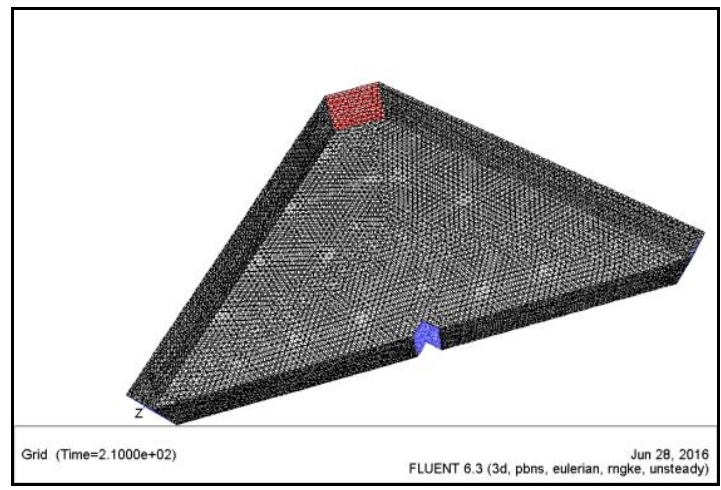

Fig.3 Meshing of Triangular mixing box

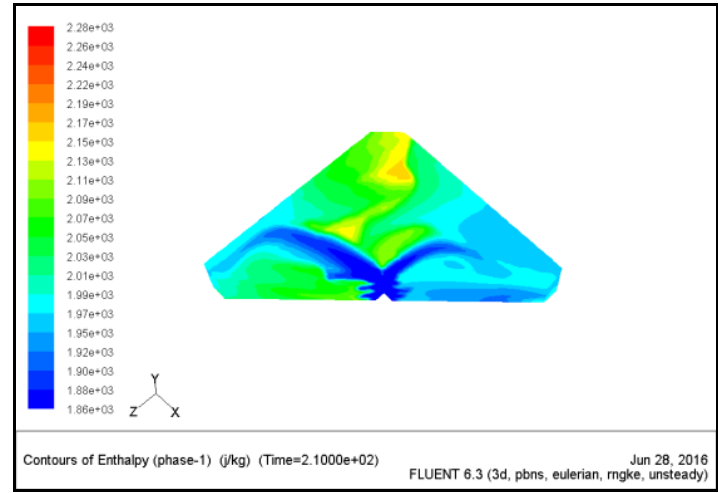

Fig.5 Enthalpy contours of Triangular mixing box

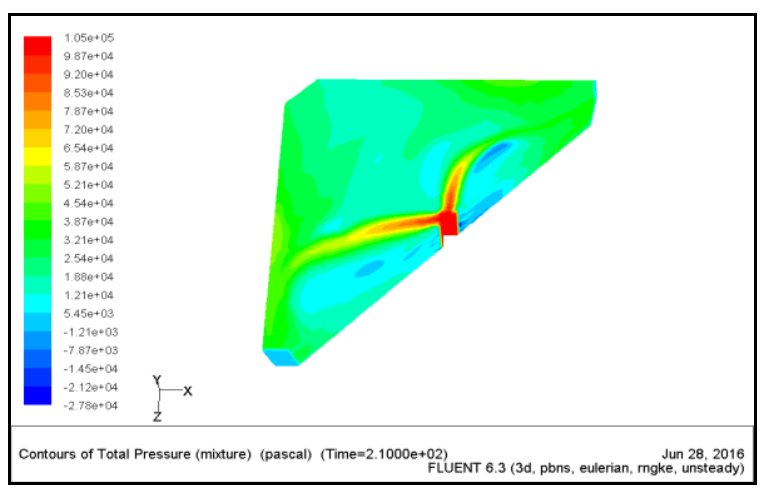

Fig.4 Pressure contours of Triangular mixing box

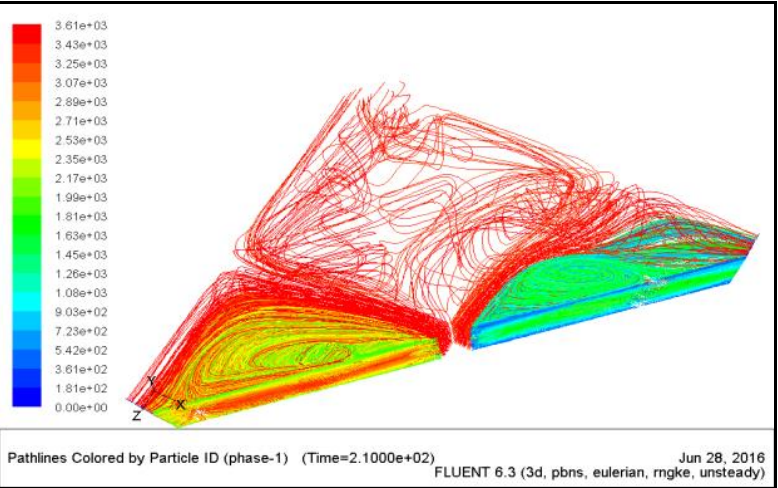

Fig.6. Path line coloured by partial of Triangular mixing box

\section{RESULTS AND DISCUSSIONS}

\section{Heat Release Rate}

Fig .7. Prostrates the crank angle and Heat release rate for three different combinations of diesel, $351 \mathrm{gm} / \mathrm{h}$ of acetylene,20\% egr with two different mixing boxes. The heat release rate is calculated based on the first law of thermo dynamics. The variations in pressure and volume at each degree of crank angle in the engine is measured by the sensors for the 100 cycles and saved in a system which is directly interfaced with the engine. It is observed in the figure7. that $80.6 \mathrm{j} / \mathrm{degree}$ crank angle of heat is recorded for diesel, acetylene of $351 \mathrm{gm} / \mathrm{h}$ with egr and triangular mixing box and with rectangular mixing box is $79 \mathrm{j} /$ degree crank angle and for pure diesel it is $76 \mathrm{j} /$ degree crank angle. In acetylene mixed diesel operation the combustion may be in two stages which includes diesel combustion first and secondly acetylene combustion initiated by the ignition of diesel. The increment of heat release rate of $2.0 \%$ was observed as compared to the heat release rate for a rectangular mixing box. This increment may due to proper mixing of air and acetylene in triangular mixing box due to the swirl created by the geometry of the mixing box and directions of supply of both air and acetylene.

\section{Peak Pressure}

Fig.8. Shows the variation of pressure and crank angle plots for various combinations of Diesel, Acetylene, Exhaust gas recirculation, with rectangular mixing box and triangular mixing box. The maximum peak pressure for only diesel operation is 71.5 bar and in duel fuel mode with $20 \%$ EGR is 74 bar. The peak pressure is further increased to 79 bar when triangular mixing box with three inlets and one out let for uniform mixture to the engine. By the addition of acetylene along with air due to rapidity in combustion and ignition delay the peak pressure by 2.5 bar. Further the peak pressure increased by $9.4 \%$ as compared with neat diesel this is due proper mixing of air and acetylene in triangular mixing box and also higher rate of combustion which accelerates the peak pressure. The 
proper mixing of air and acetylene in a triangular mixing box is due to the geometry of the mixing box and the directions of supply of air and acetylene the swirl was created which leads to uniform mixture to the engine.

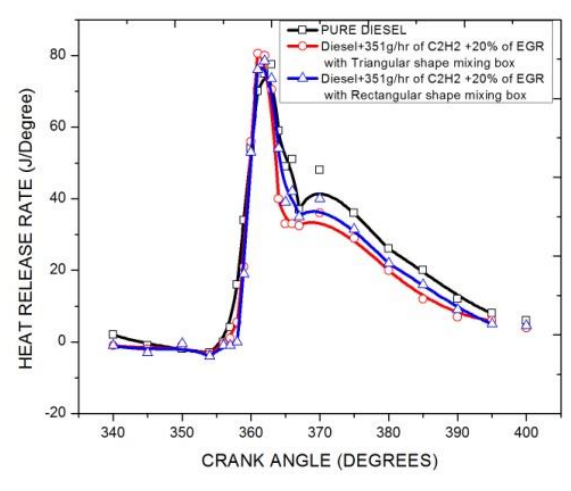

Fig. 7. Crank angle Vs Heat release rate

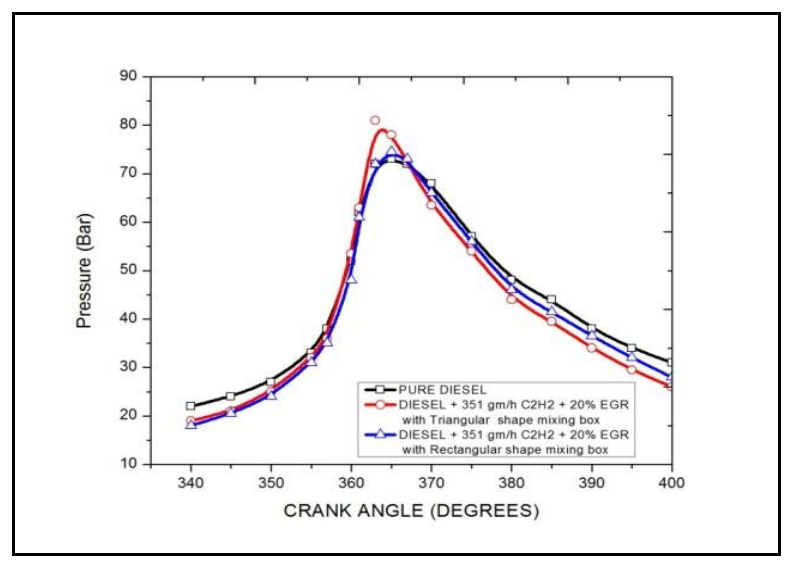

Fig. 8. Crank angle Vs Pressure

\section{Break Thermal Efficiency}

Figure no.9. Represents the variations of break thermal efficiency at different loads. At lower rate of loads there is no much variations in break thermal efficiencies were observed for all the combinations. The break thermal efficiency with a rectangular mixing box at $50 \%$ load is $22 \%$ and for triangular mixing box and for pure diesel at $50 \%$ load is $23.5 \%$. The break thermal efficiency is decreesing in duel fuel mode as compared with pure diesel. By mixing air and acetylene in new designed mixing box more uniformly prior to the supply to the engine there is no compromise in break thermal efficiency. This may be due to the effectiveness of the uniform mixture and the technique of new mixing box is working effectively. At maximum load the break thermal efficiency curve is deviating as compared with pure diesel and also there is little increment in break thermal efficiency with triangular mixing box as compared to rectangular mixing box.

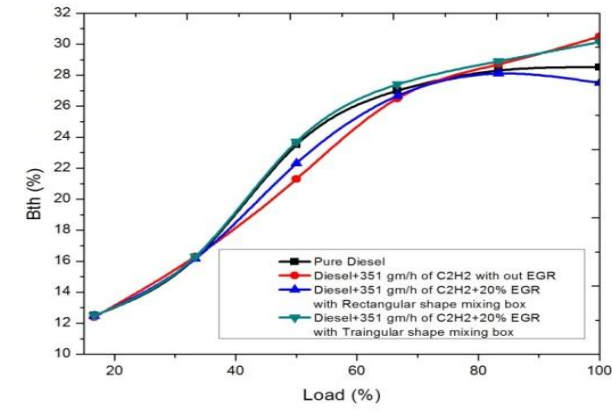

Fig. 9.Load Vs Bth

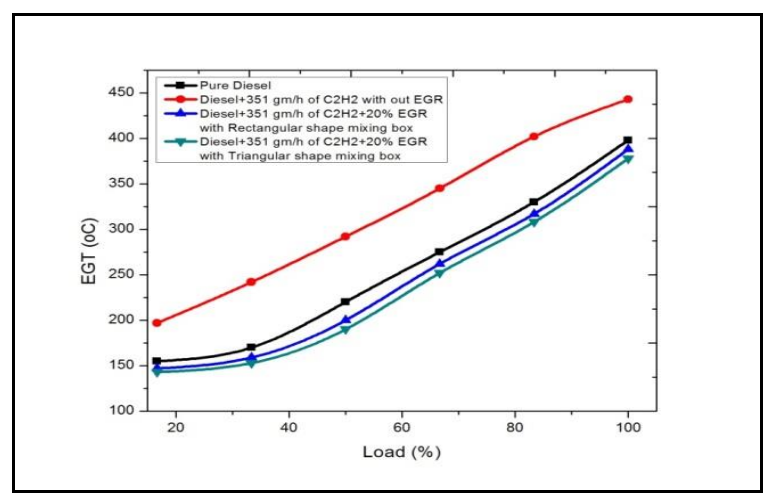

Fig. 10. Load Vs EGT

\section{Exhaust Gas Temperature}

Fig .10. shows the plot between Load and Exhaust gas temperature. It is more interesting to know that the exhaust gas temperature increased in acetylene diesel operation in duel fuel mode. The exhaust gas recirculation technique in duel fuel mode of operation reduces the exhaust gas temperature. The reason for reduction of the exhaust gas temperature with EGR technique is the inlet charge is diluted with exhaust gases up to certain extent and reduces the temperature of the combustion. Furthermore the exhaust gas temperature is reduced by another $4 \%$ at all the loads 
due to the addition of triangular mixing box as compared with the rectangular mixing box, this may be due to uniform mixture of air and acetylene due to swirl created and accelerated the intensity of mixing.

\subsection{Oxides of Nitrogen}

Fig.11. Shows the plot between various loads and oxides of nitrogen with different combinations of diesel, acetylene, egr, rectangular mixing box and a triangular mixing box. The oxides of nitrogen at $50 \%$ load for a pure diesel $13.1 \mathrm{gm} / \mathrm{kwh}$, in duel fuel mode with acetylene is $14.3 \mathrm{gm} / \mathrm{kwh}$, and with the technique of EGR of $20 \%$ is $13.2 \mathrm{gm} / \mathrm{kwh}$ and with the same combination including triangular mixing box is $12.4 \mathrm{gm} / \mathrm{kwh}$.In duel fuel mode of operation without EGR there is an increment of $8.4 \%$ of Nox were observed. At the same load with $20 \%$ EGR the Nox emissions are reduced by $3 \%$ as compared with pure diesel and by introducing a new mixing box further the Nox reduced by $4.6 \%$ as compared with pure diesel operation. With the addition of EGR the oxygen level decreases.

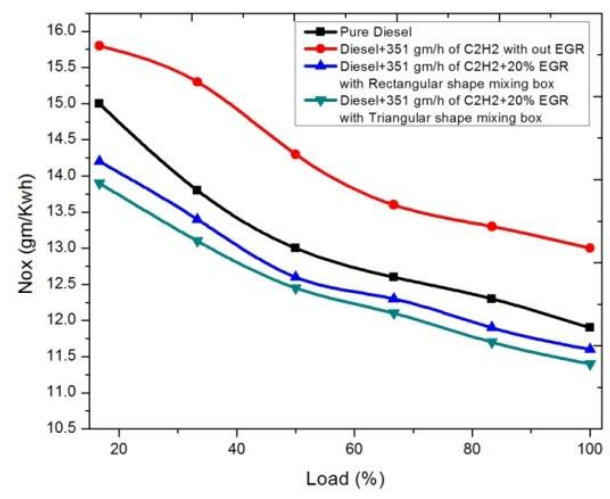

Fig.11.Load Vs Nox

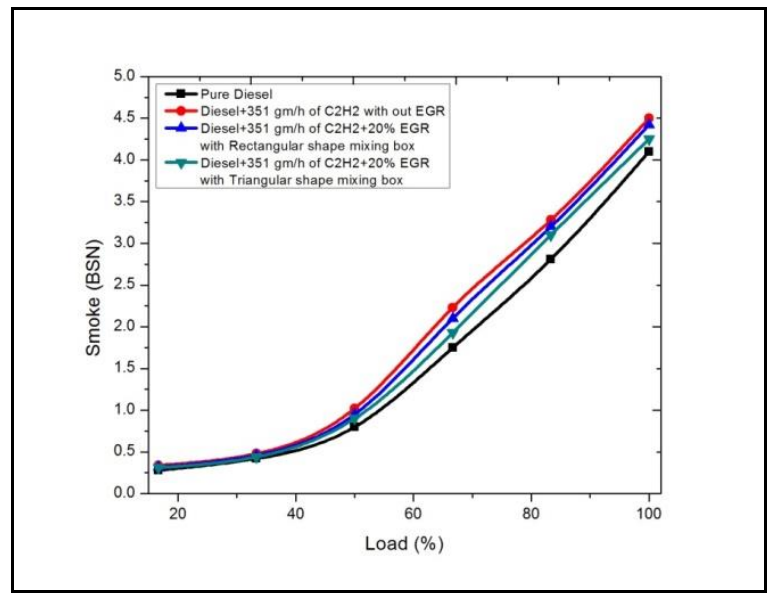

Fig. 12.Load Vs Smoke

Smoke

Fig. 12.represents the changes in smoke levels with respect to load. At higher loads the smoke level will be generally higher because of excess of diesel supply. At maximum load 4.2 BSN is the smoke level for only diesel. Similarly at same maximum load in case of acetylene inducted without egr is $4.5 \mathrm{BSN}$, and with $20 \%$ egr is 4.4 BSN. With the use of new designed triangular mixing box the smoke level reduced to $4.3 \mathrm{BSN}$. The smoke level is marginally reduced by $2.3 \%$ with new mixing box compared with rectangular mixing box and smoke level is almost reaching to the smoke level of the pure diesel. This reduction in smoke level is due to uniform mixing of air and acetylene in new mixing box.

\section{Carbon monoxide (Co)}

Fig.13. shows the variation of carbon monoxide emissions with respect to load. The carbon monoxide emissions are less as compared with pure diesel at all loads. At $50 \%$ load the emissions of Co is $3.8 \mathrm{gm} / \mathrm{kwh}$ for pure diesel and acetylene added duel fuel mode without egr Co is $2.2 \mathrm{gm} / \mathrm{kwh}$ the reduction in Co emission is due to addition of acetylene which increase the flame speed. Acetylene added duel fuel mode with $20 \%$ egr there is an increment in Co emissions but less than only diesel operation due to less oxygen presence in the combustion chamber. With use of uniform mixing technique Co emissions marginally reduced as compared with the earlier one.

\section{Carbon dioxide $\left(\mathrm{Co}_{2}\right)$}

Fig.14. presents the variation of load and $\mathrm{Co}_{2}$ emissions. For pure diesel at $100 \%$ load the $\mathrm{Co}_{2}$ emissions are 865 $\mathrm{gm} / \mathrm{kwh}$ and $650 \mathrm{gm} / \mathrm{kwh}$ in acetylene with diesel operation. The reduction in $\mathrm{Co}_{2}$ level is due to less carbon and 
hydrogen ratio. With $20 \%$ egr in duel fuel mode of operation the carbon dioxide emissions were increased by $21 \%$ as compared without egr due to presence of more carbon dioxide present in exhaust gas recirculation.

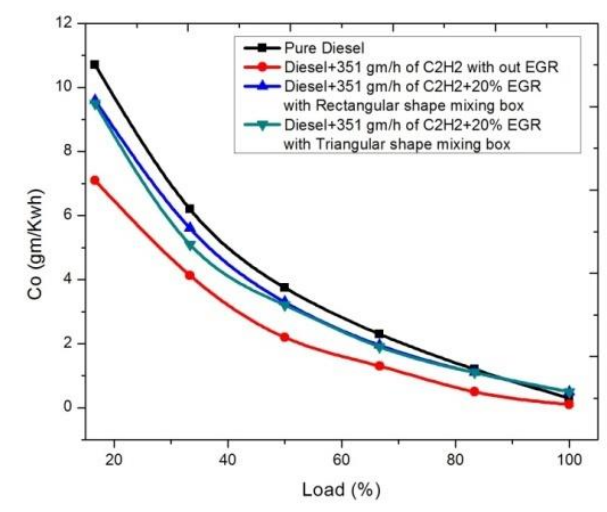

Fig. 13.Load Vs Co

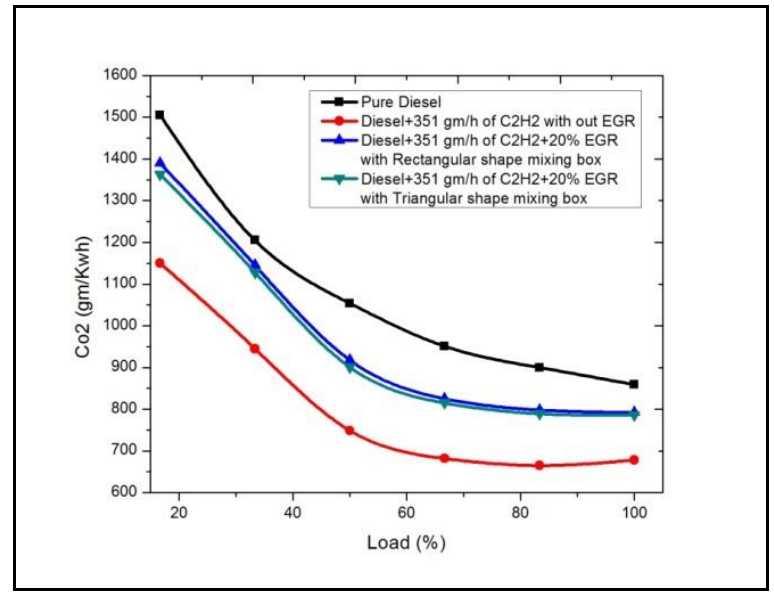

Fig. 14.Load Vs $\mathrm{Co}_{2}$

\section{Hydro Carbon $(\mathrm{Hc})$}

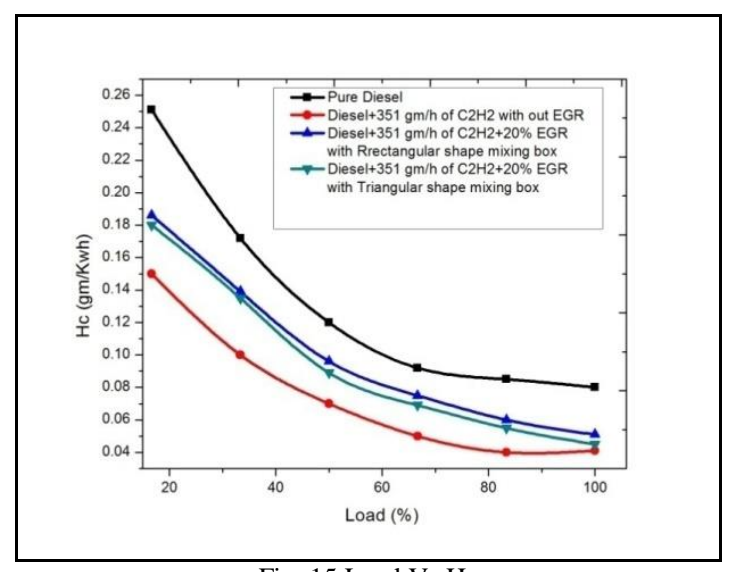

Fig. 15.Load Vs Hc

Fig.15. shows the variation of Hc emissions at various loads. For only diesel operation Hc emissions at $50 \%$ load is $0.12 \mathrm{gm} / \mathrm{kwh}$,in duel fuel mode without egr is $0.070 \mathrm{gm} / \mathrm{kwh}$ and with $20 \%$ egr is $0.095 \mathrm{gm} / \mathrm{kwh}$ and with new mixing box $0.087 \mathrm{gm} / \mathrm{kwh}$. There is considerable reduction in Hc emission with acetylene as compared with pure diesel operation due to fast combustion nature of the acetylene gas. With $20 \%$ egr again Hc increased but less than pure diesel due to less oxygen presence make combustion incomplete. By using triangular mixing box Hc emissions are further reduced.

\section{CONCLUSIONS}

I.The experiments were performed to investigate the effect of performance and emissions characteristics of afour stroke water cooled diesel engine by supplementing acetylene and also with the help of mixing box and the following conclusions are made based on the experimental results.

II. A three dimensional mixing boxes of different shapes with different inlet and outlet positions are designed and analysis has been done in CFD. Based on the simulation results plotted in velocity, pressure and enthalpy plots, the optimum shape of the mixing box is designed. 
III. The geometry, positions and directions of inlets and outlets of a mixing box gave uniform mixture of air and acetylene (Air from the atmosphere and acetylene from the acetylene generator) by swirl

IV. Brake thermal efficiency in a acetylene aspirated engine mode is less than pure diesel operation at lower loads, due to the continuous supply of acetylene in the intake. The break thermal efficiency at $100 \%$ loads little higher than the pure diesel operation due to the proper mixing of air and acetylene in a triangular mixing box

V.The Nox levels can be controlled by Exhaust gas recirculation technique. By the addition of acetylene with diesel Nox levels were increased by $8.7 \%$ at a specific load and $20 \%$ of EGR reduces the Nox level by $3.4 \%$. and $4.6 \%$ reduction in Nox due to uniform mixing of air and acetylene.

VI.The smoke level for pure diesel operation is 4.2 BSN and 4.5 BSN for acetylene aspirated engine with diesel which is $6.6 \%$ increment in smoke level. With EGR and supply of uniform mixture of air and acetylene the smoke level is reduced to 4.3 BSN. The smoke level obtained with the EGR and uniform mixture technique is almost reaching to the smoke level of pure diesel operation.

VII. The emissions like $\mathrm{Hc}, \mathrm{Co}_{2}$, $\mathrm{Co}$ are considerably reduced in acetylene added diesel engine with improved geometry of mixing box as compared with pure diesel operation. By EGR application there is slight increment of all the $\mathrm{Hc}, \mathrm{Co}_{2}$, $\mathrm{Co}$ emissions but lower than as compared to the pure diesel operation. $\mathrm{Hc}, \mathrm{Co}_{2}, \mathrm{Co}_{\mathrm{emissions}}$ are reduced by $5 \%, 2.2 \%$ and $5.7 \%$ respectively with the designed new mixing box.

VIII.In dual fuel operation of acetylene and diesel exhibits higher exhaust gas temperature as compared to the pure diesel operation. There is 5\% reduction of exhaust gas temperature at $50 \%$ load and $2.7 \%$ reduction at $100 \%$ load with the application of new designed mixing box.

IX.There is a slight increment in peak pressure and heat release rate and negligible advancement due to proper mixing of air and acetylene and also due to high flame speed of acetylene.

X.At lower loads to medium loads the acetylene giving fare results in combustion but at higher loads acetylene contribution in combustion is not up to the mark

\section{REFERENCES}

[1] P.K. Sharma, H. Kuinkel, P. Shrestha and Suman Poudel, "Use of Acetylene as an Alternative Fuel in IC Engine", Rentech Symposium Compendium, Vol.-1, March 2012

[2] T. Lakshmanan, G. Nagarajan" Study on using acetylene in dual fuel mode with exhaust gas recirculation",International journal of energy Elsevier,Energy36(2011) 3547-3553.

[3] T. Lakshmanan, G. Nagarajan "Experimental investigation of port injection of acetylene in DI diesel enginein dual fuel mode, International journal of Fuel Elsevier,Fuel90(2011),2571-2577

[4] S.K.Mahla, Som Kumar, Harshdeep Shergill and Ashwani Kumar "Study the Performance Characteristics Of Acetylene Gas In Dual Fuel Engine With Diethyl Ether Blends"

[5] C. Gunea, M.R.M. Razavi, G.A. Karim, "The effects of pilot fuel quantity on dual-fuel engine ignition delay". SAE PaperNo 982453, 1998.

[6] John W.H.Price, An acetylene cylinder explosion: A most probable cause analysis, Engineering Failure Analysis 13(2006) 705-715.

[7] SwamiNathan S, Mallikarjuna JM, Ramesh A. HCCI engine operation withacetylene the fuel. SAE paper no 2008-28-0032.

[8] Beach, R.; Prahl, D.; Lange, R. (2013). CFD Analysis of Flexible Duct Junction Box Design. Golden, CO: National Renewable Energy Laboratory. DOE/GO-102013- 4297.

[9] Burdick, A. (2011a). Advanced Strategy Guideline: Air Distribution Basics and Duct Design. Golden, CO: National Renewable Energy Laboratory. NREL/SR-5500-53352.

[10] Holman JB. Experimental techniques for engineers. New Delhi: Tata McGraw-Hill Publishing Company Limited; 2004.

[11] Patro TN. Combustion study of hydrogen fueled DI diesel engine: simplifiedheat release analysis. International Journal of Hydrogen Energy 1993;18:231e41.

[12] Ladommatos N, Abdelhalim SM, Zhao H, Hu Z. Effects of EGR on heat release indiesel combustion, SAE Transactions 980184. 
[13] Heywood JB. Internal combustion engine Fundamentals. Singapore: McGrawHill Book Company; 1998.

[14] Rao H, Shrivastava KN, Bhakta NH. Hydrogen for dual-fuel engine operation.International Journal of Hydrogen Energy 1983;8:381e4.

[15] Tomita E, Kawahara N, Piao Z, Fujita S, Hamamoto Y. Hydrogen combustionand exhaust emissions ignited with diesel oil in a dual-fuel engine. SAE PaperNo 2001-01-3503.

[16] Karim GA. The dual-fuel engine of the compression ignition type-prospects,problems and solutions: a review, SAE Paper No 831073

[17] O. Angrill, H. Geitlinger, T. Streibel, R. Suntz, H. Bockhorn, Influence of Exhaust Gas Recirculation on Soot Formation in Diffusion Flames, Proceedings of the combustion Institute, Vol. 28, 2000, pp. 2643-2649.

[18] A. Maiboom, X. Tauzia, J-F. Hetet, Experimental Study of Various Effects of Exhaust Gas Recirculation (EGR) on Combustion and Emissions of an Automotive Direct Injection Diesel Engine, Energy, Vol. 33, 2008, pp. 22- 34. 